\title{
ADAMTS-1 Expression in Cumulus Cells: A Biomarker for Oocyte Maturity
}

\section{Sepide Gohari Taban', Iraj Amiri², Massoud Saidijam³ ${ }^{3}$, Sara Soleimani Asl ${ }^{4}$, Mahnaz Yavangi $^{5}$, Elham Khanlarzadeh ${ }^{6}$, Tayebe Artimani ${ }^{7, *}$}

${ }^{1}$ MSc in Anatomy, Hamadan University of Medical Sciences, Hamadan, Iran

${ }^{2}$ Professor of Anatomy, Endometrium and Endometriosis Research Center, Hamadan University of Medical Sciences, Hamadan, Iran

${ }^{3}$ Professor of Molecular of Biology, Research Center for Molecular Medicine, Hamadan University of Medical Sciences, Hamadan, Iran

${ }^{4}$ Associate Professor of Anatomy, Endometrium and Endometriosis Research Center, Hamadan University of Medical Sciences, Hamadan, Iran

${ }^{5}$ Associate Professor of Obstetrics and Gynecology, Endometrium and Endometriosis Research Center, Hamadan University of Medical Sciences, Hamadan, Iran

${ }^{6}$ Assistant Professor, Department of Community Medicine, School of Medicine, Hamadan University of Medical Sciences, Hamadan, Iran

${ }^{7}$ Assistant Professor of Reproductive Biology, Endometrium and Endometriosis Research Center, Hamadan University of Medical Sciences, Hamadan, Iran

* Corresponding Author: Tayebe Artimani, Endometrium and Endometriosis Research Center, Hamadan University of Medical Sciences, Hamadan, Iran.Email: artimani@umsha.ac.ir

Received: 24.09 .2017

Accepted: 15.01 .2018

How to Cite this Article: Gohari Taban S, Amiri I, Saidijam M, Soleimani Asl S, Yavangi M, Khanlarzadeh E, Artimani T. ADAMTS-1 Expression in Cumulus Cells: A Biomarker for Oocyte Maturity. Avicenna J Clin Med. 2018; 24(4): 263-269. DOI: 10.21859/ajcm.24.4.263.

\section{Abstract}

Background and Objective: Cumulus cells regulate oocyte maturation through bilateral communication during follicular growth. Expression of disintegrin-like and metalloproteinase with thrombospondin type I motifs-1 (ADAMTS-1) is essential for structural remodeling during the follicle growth, to maintain normal granulosa cell layers in the follicles. Since limited studies have been performed on this issue, we aimed to evaluate the expression of ADAMTS-1 in human cumulus cells and the possible correlation between ADAMTS-1 expression and oocyte maturity.

Materials and Methods: Fifty infertile women aged $18-40$ years undergoing in vitro fertilization (IVF) were recruited. The participants had tubal obstruction and/or their partners were diagnosed with male factor infertility. Cumulus cells were obtained immediately after the isolation of cumulusoocyte complexes. Adamts- 1 and $\beta$-actin mRNA expression levels were measured using quantitative real-time polymerase chain reaction (qRTPCR).

Results: PCR results showed expression of ADAMTS-1 in cumulus cells. qRT-PCR demonstrated an increased expression of ADAMTS- 1 in cumulus cells of mature oocyte compared to the vesicle-stage (GV) oocyte $(\mathrm{P}=0.02)$. It is worth mentioning that 5.14 was considered the cut-off point for determining the false and true negative results. Moreover, sensitivity and specificity of the ADAMTS-1 were $90 \%$ and $67 \%$, respectively (an area under the ROC curve of 0.8 ).

Conclusion: ADAMTS- 1 expression was remarkably lower in GV oocytes than the mature ones, and it can be considered as a specific biomarker in cumulus cells separated from oocytes for determining the rate of oocyte maturation.

Keywords: ADAMTS-1, Cumulus Cell, Oocyte Maturity 
10.21859/ajcm.24.4.263

\title{
بيان ADAMTS-1 در سلولهاى كومولوس: بيومار كرى براى تعيين بلوغ اووسيت
}

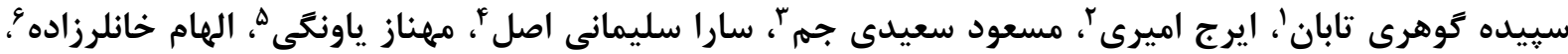 طيبه آرتيمانى v.v}

\author{
' كارشناسى ارشد آناتومى دانشكاه علوم يزشكى همدان، همدان، ايران

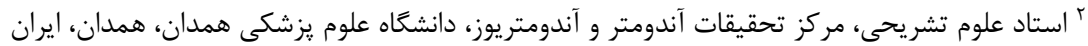

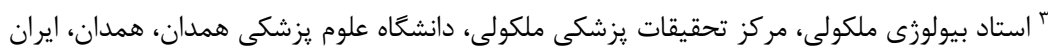



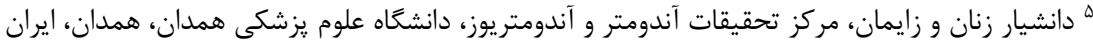

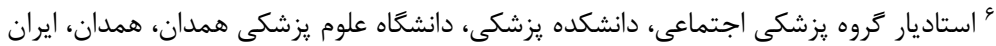

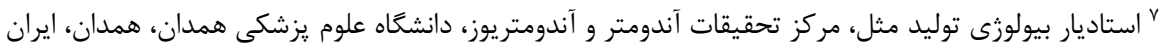 \\ "* نويسنده مسئول: طيبه آرتيمانى، مركز تحقيقات آندومتر و آندومتريوز، دانشكاه علوم يزشكى همدان، همدان، ايران. \\ ايميل: artimani@umsha.ac.ir
}

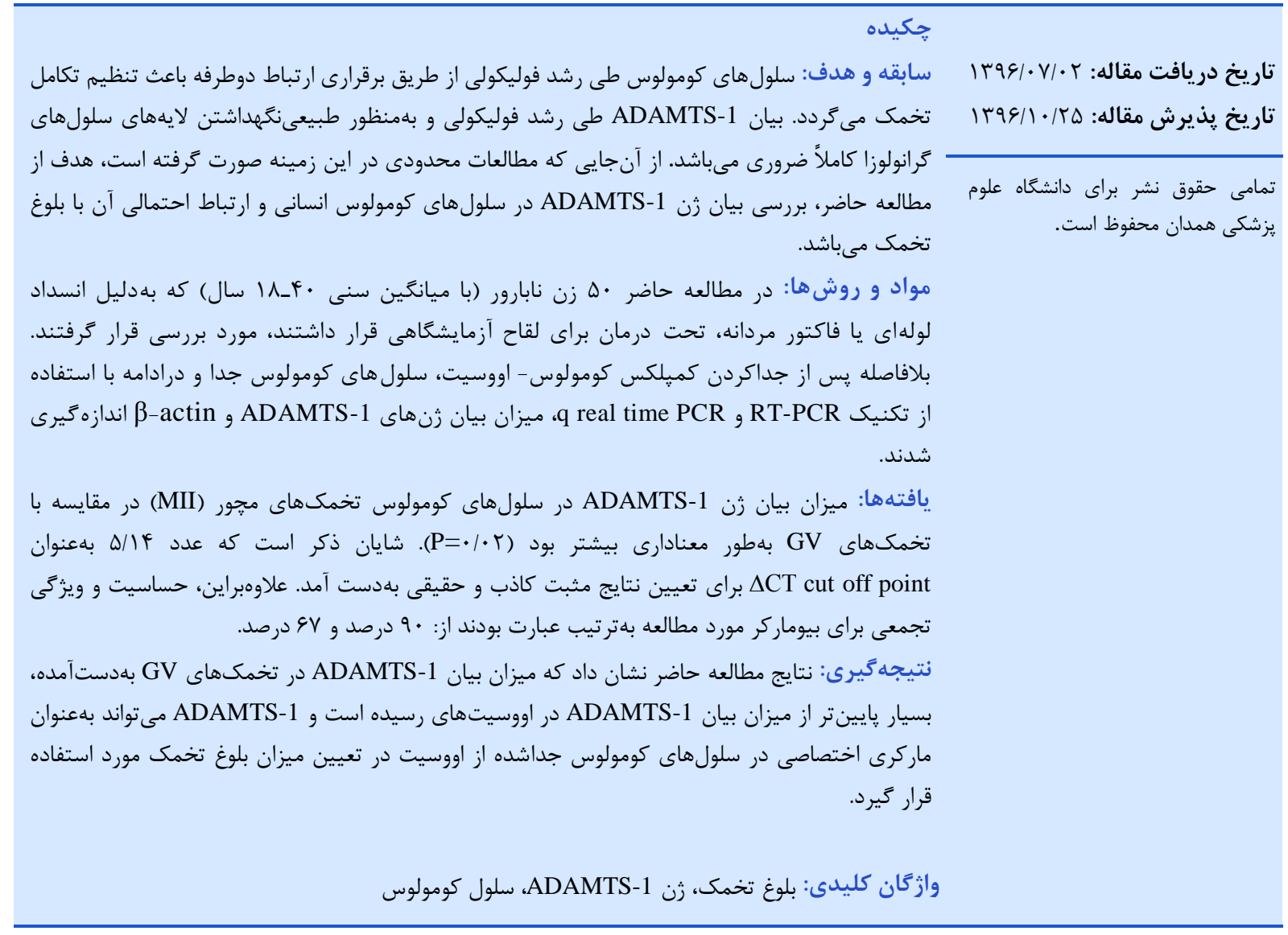

آن به لحاظ رشد و تكامل كاملا به يكديكر وابسته مىباشند [ــ].]

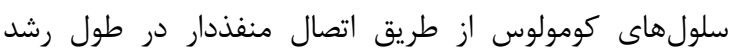

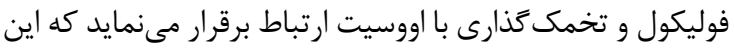

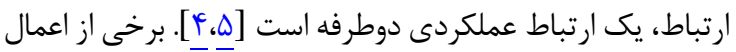

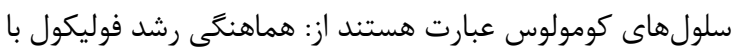

سلولهاى كومولوس، زيرگروهى از سلولهاى كرانولوزا

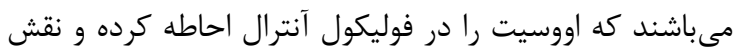

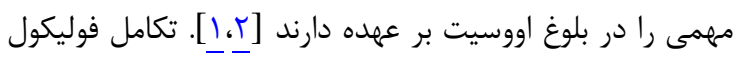

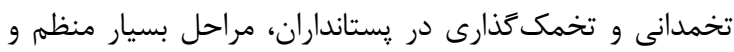

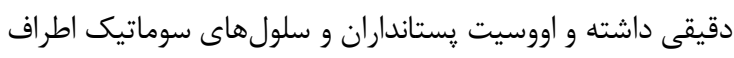


[10] و نيز از آنجايى كه مطالعات محدودى در اين زمينه انجام

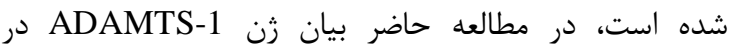
سلولهاى كومولوس و ارتباط آنها با كيفيت تخمك و همجنين

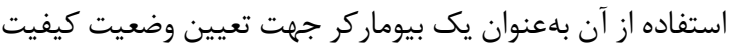
تخمك مورد بررسى و مطالعه قرار كرفت.

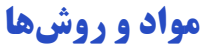

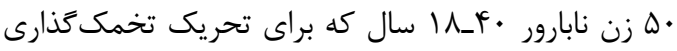

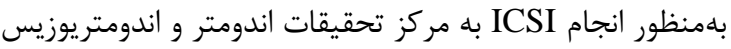

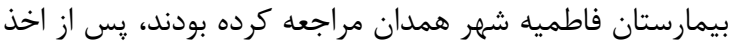



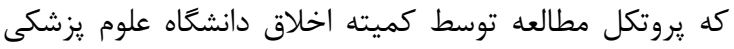
همدان (به شماره:

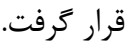

شركتكنندكان در مطالعه را زنان فاقد هركونه بيمارى تخمدان كه بهدليل فاكتور مردانه يا فاكتور لولهان باى به ائ اين مركز

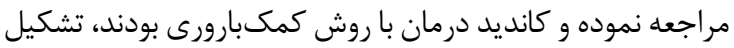

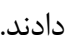
جهت انجام مطالعه، غلظت FSH و LH سرم در روز سوم سيكل با استفاده از كيت ايمنو اسى الكترو كمينواسانس

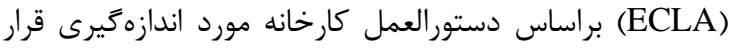

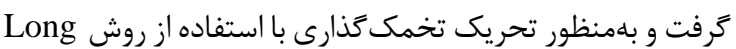

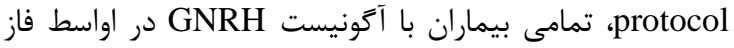

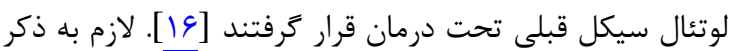
است كه Gonal-F, Merk Serno, ) Recombinant FSH ICSI و IVF براى تحريك تخمدانى طى سيكل (Switzerland

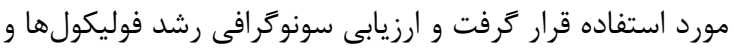

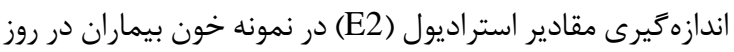

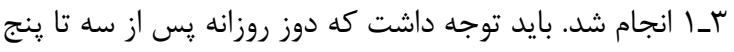



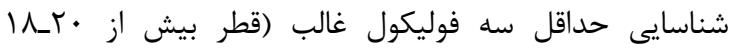

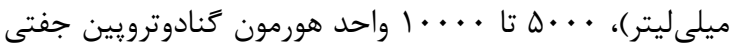
براى (HCG, Choriomon, IBS, Lungano, Switzerland)

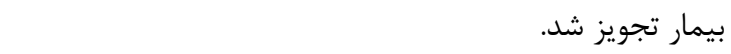

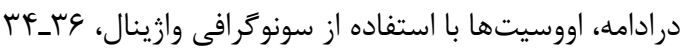
ساعت يّ از تجويز HCG از تخمدانها آسبيره كرديدند و

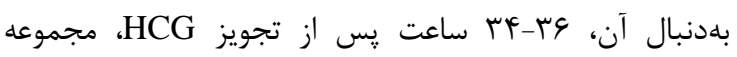
كومولوس- اووسيت (COC) جدا ترديد. در اين مرحله،

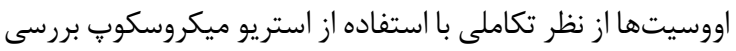

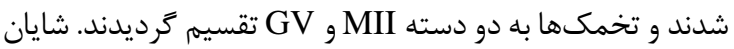

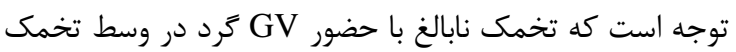
و وجود سلولهاى كومولوس فشرده در اطراف تخمك مشخص

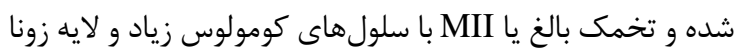
و و اوويلاسم واضح شناسايى مى تردند.
بلوغ اووسيت، توليد انرزى براى تكميل تقسيم ميوز در اووسيت،

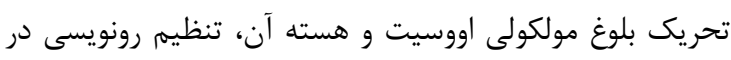
اووسيت، تحريك انتقال آمينواسيد و بيوسنتز استرول، توسعه

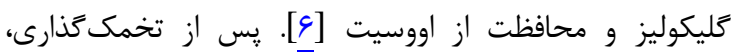
سلولهاى كومولوس ارتباط خود را با اووسيت حفظ مى كنند تا لـأ

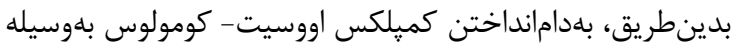

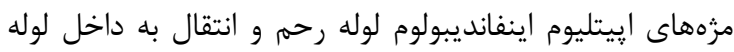

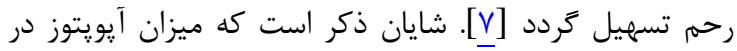



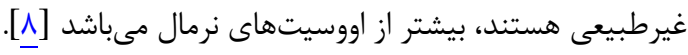

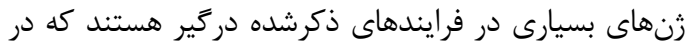

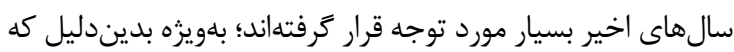

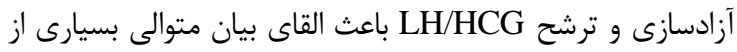

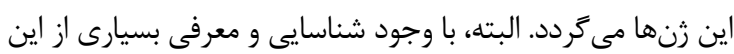

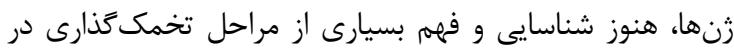

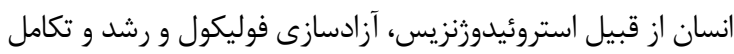
اووسيت امكانيذير نمىباشد. A Disintegrin ) ADAMTS1 (and Metalloproteinase with a Thrombospondin Motif كروهى از يروتئازها هستند كه اعضاى مختلف آن نقشى كليدى در

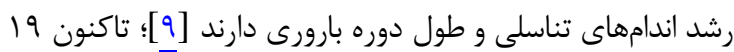
عضو از اين خانواده كشف شده است. اين آنزيمها كه در ماتر داتر دايكس

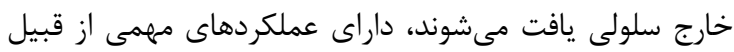



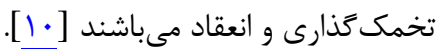
ADAMTS1

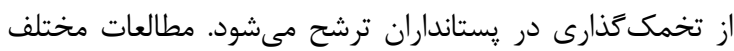

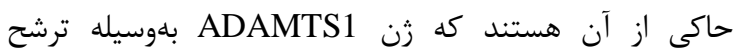



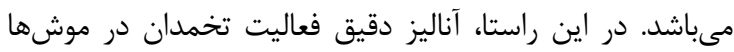
نشان داده است كه ADAMTS1، فاكتورى ضرورى براى بازسازى فئي ساختارى طى رشد فوليكول تخمدانى، ثبات و حفظ لايههاى

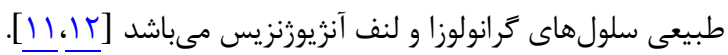

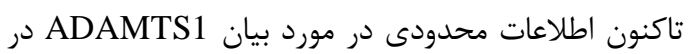

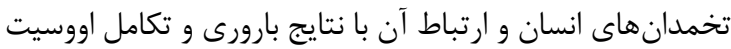

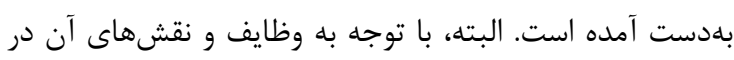

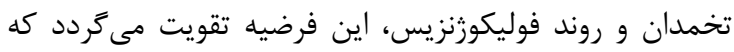

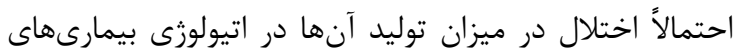



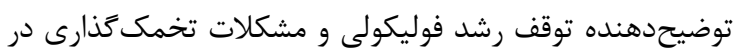

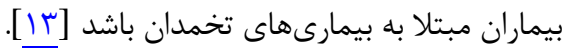

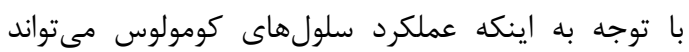

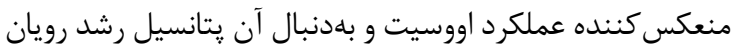
باشد [F] ب و ضمن تأكيد بر اينكه استفاده از سلولهاى

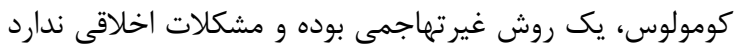


ديكر، بررسى كمى بيان زن ADAMTS-1 توسط دستگاه LightCycler ( 96 System, Roche, ) Real Time PCR (Germany با استفاده از يرايمرهاى اختصاصى كه توسط يزوهشكر

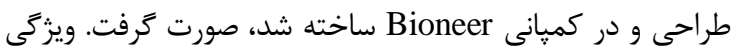
يرايمرهاى مورد استفاده در جدول الى الرائه شده است. درادامه،


V أميكروليتر ماسترميكس سايبر كرين (Takara, Hapan)،

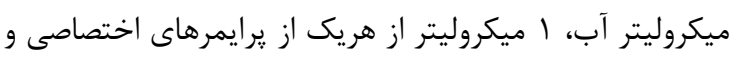
ا ميكروليتر cDNA انجام شد. شايان ذكر است كه ير يروفايل

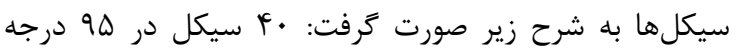
سانتى

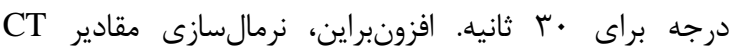

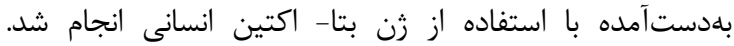

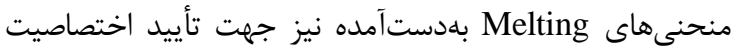

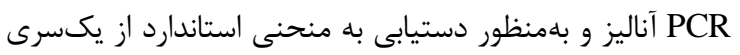
رقت لمَاريتمى RNA استفاده كرديد. درادامه، نتايج با استفاده از

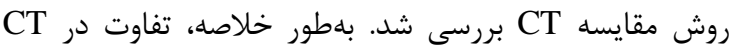

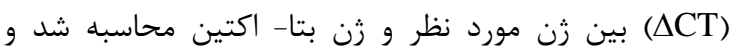
درنهايت، از روش

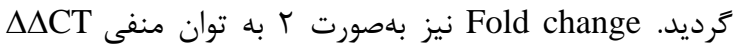

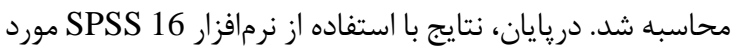
بررسى قرار كرفت و بلصورت ميانكَينثانحراف معيار ارائه كرديد.

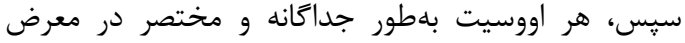

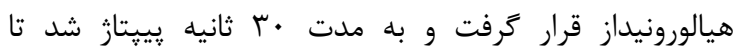

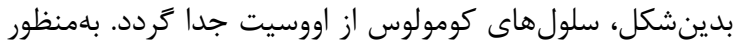

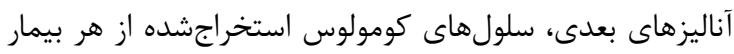

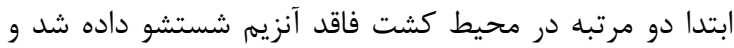

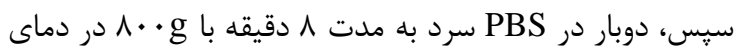

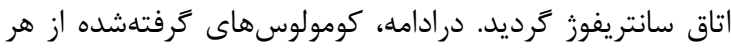

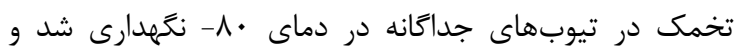

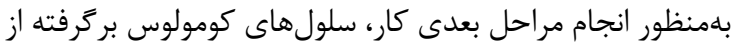

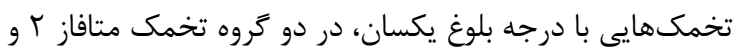

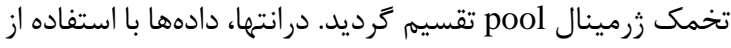

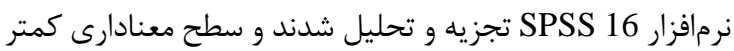

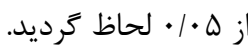

پس از اضافهردن ا سى سى آكازول (Accuzol) (ساخت

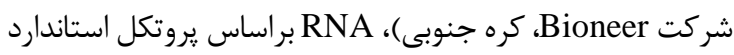

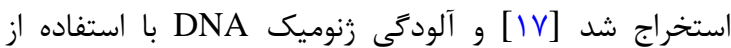

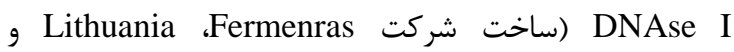
(Vilnius از كل RNA بهدست آمده حذف ترديد. سيس،

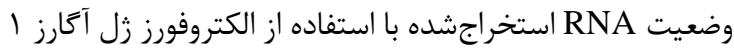

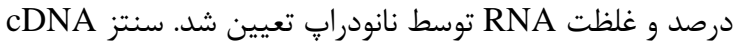

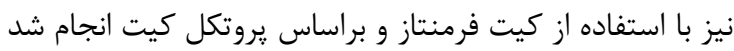

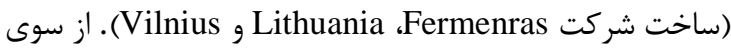

جدول ا: ويزَّى : يرايمرهاى مورد استفاده

\begin{tabular}{|c|c|c|}
\hline اندازه توالى (bp) & توالى برايمر & 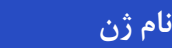 \\
\hline FFF & $\begin{array}{l}\text { F: CCAGACCTTGTGCAGACCAT } \\
\text { R: TCACTTTGCCTTGCCCTCAA }\end{array}$ & ADAMTS-1 \\
\hline IVV & $\begin{array}{l}\text { F:AAGATCAAGATCATTGCT } \\
\text { R:TAACGCAACTAAGTCATA }\end{array}$ & $\beta$-actin \\
\hline
\end{tabular}

يافته ها

بيان ثن ADAMTS-1 در سلول هاى كومولوس

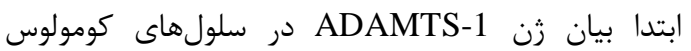
بهدست آمده از كميلكس كومولوس - اووسيت زنان تحت تحريك



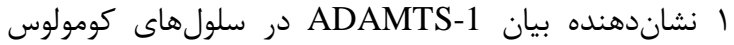

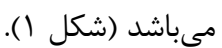
سيس، بهمنظور بررسى ارتباط بين ميزان تكامل اووسيت و

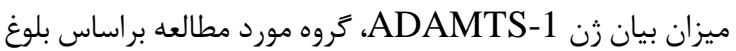

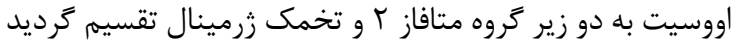

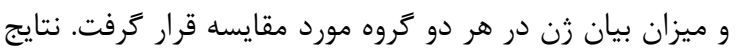

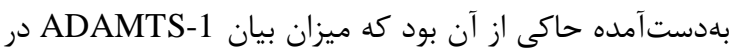
كروه متافاز r بلهور معنادارى بيشتر از كروه GV

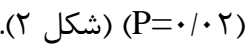

افزونبراين، بهمنظور ارزيابى توانايى تشخيصى

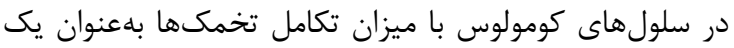

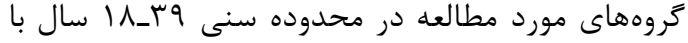

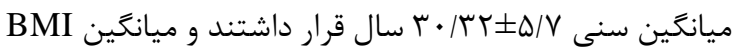

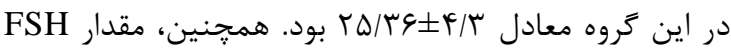
קايه (IU)

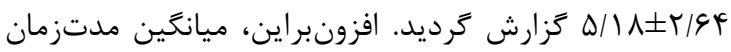
نابارورى افراد شركت كننده در مطالعه معادل

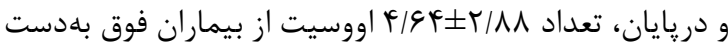

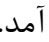

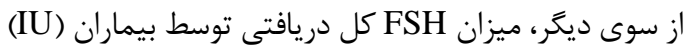

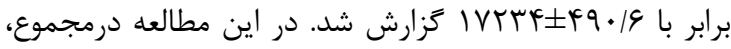

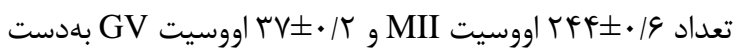
آمد و مورد بررسى قرار كرفت. لازم به ذكر است كه از كل

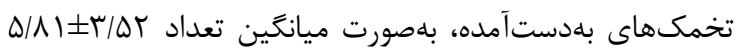

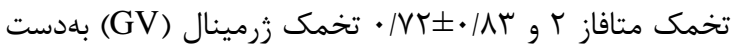

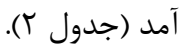


جدول ب: مشخصات دموگر افيك و بالينى افراد مورد مطالعه

\begin{tabular}{|c|c|}
\hline انحراف معيار ذميانكين & متغير \\
\hline$r T / r \cdot \pm V / \Delta$ & سن (سال) \\
\hline$r \varphi / r \Delta \pm r / \mathcal{F}$ & BMI \\
\hline $\mid F / V \pm r F / r$ & FSH \\
\hline $\mid N / \Delta \pm G K / T$ & LH يايه (IU) \\
\hline$r / V \pm \varphi 9 / \varphi$ & مدتزمان نابارورى \\
\hline$\varepsilon F / F \pm \Lambda \Lambda / r$ & تعداد اووسيت \\
\hline IVTrKES/Fq. & Fل دريافتى توسط بيماران (IUSH \\
\hline TFF士G/. & تعداد كل اووسيت MII \\
\hline$r V \pm r / \cdot$ & تعداد كل اووسيت GV \\
\hline$\Lambda 1 / \Delta \pm \Delta r / r$ & ميانكين اووسيت MII بهدستآمده از هر بيمار \\
\hline$V r / \cdot \pm \lambda r / \cdot$ & ميانخين اووسيت GV بهدستآمده از هر بيمار \\
\hline
\end{tabular}

كانديد ماركر از منحنى ROC استفاده گرديد. آناليز منحنى

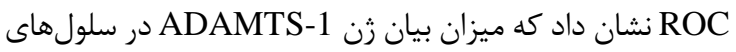

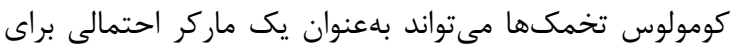

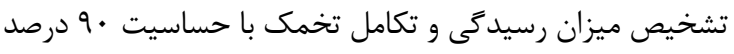

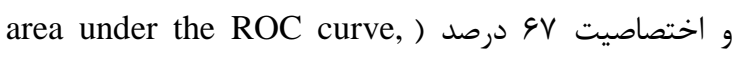

$$
\text { (AUC:0.8 درنظر كرفته شود. }
$$

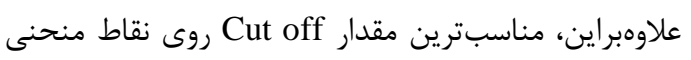

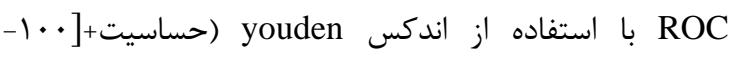
ويزگگى]) با محاسبه حداكثر مقدار تعيين گرديد. در اين راستا،

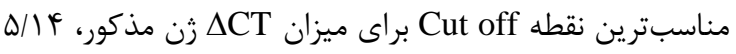
ييشنهاد مى مردد. A $\quad$ B $\quad$ C $\quad$ D

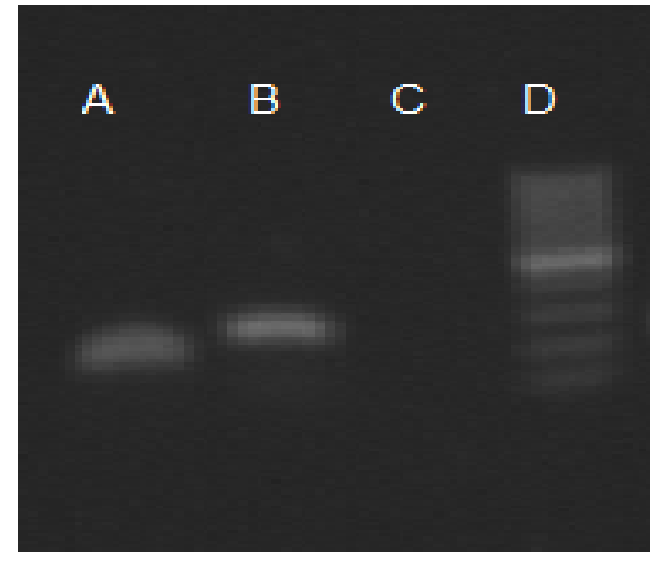

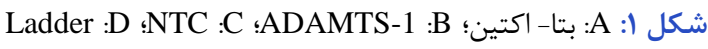

\section{ADAMTS-1}

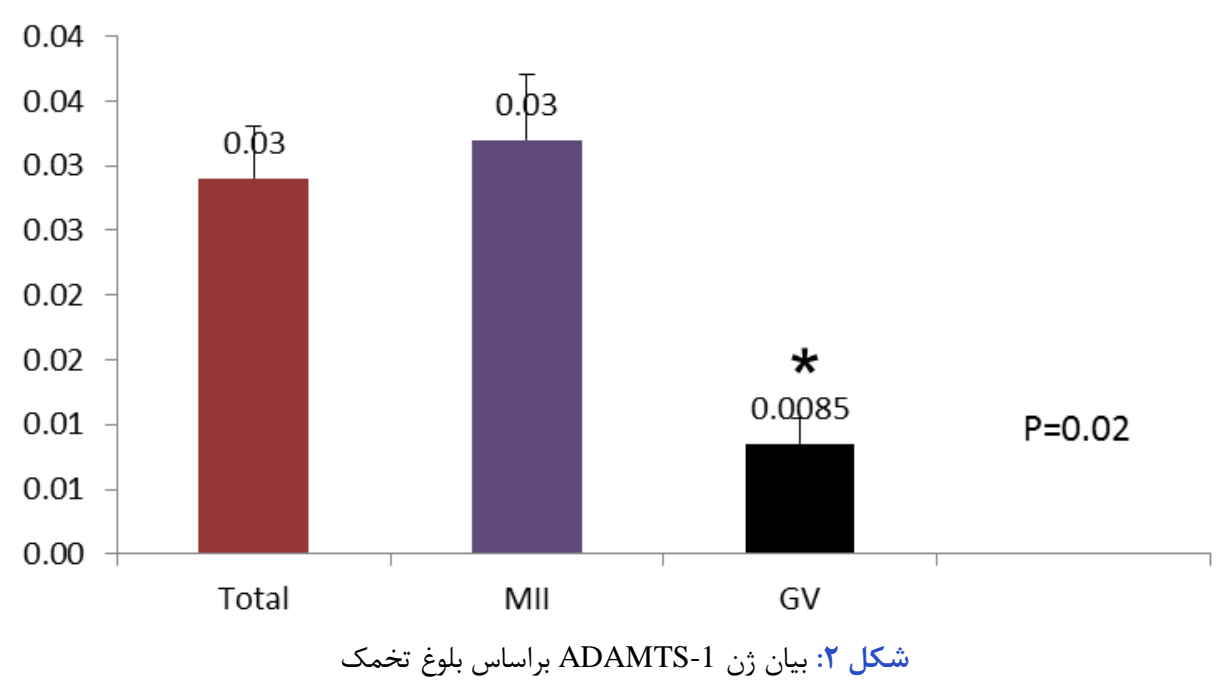

ADAMTS-1

تخمك گذارى بهمنظور انجام IVF/ICSI بودند، با استفاده از qRT-PCR
ADAMTS-1

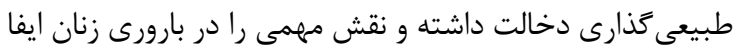

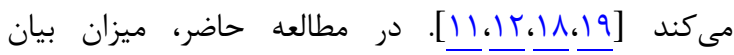


[rار] ارتباط معنادارى را بين ميزان بيان ADAMTS-1

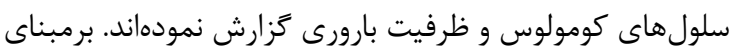

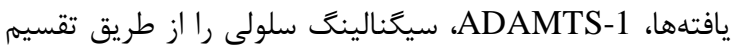

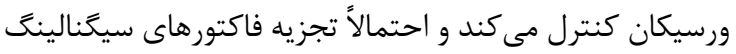

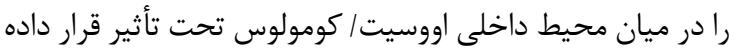

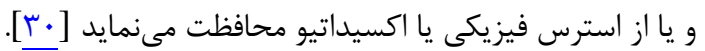
شايان توجه است كه حساسيت و ويزگى مقادير

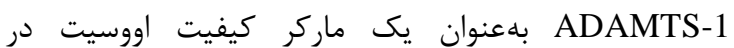
سلولهاى كومولوس با استفاده از آناليز منحنى ROC إكير

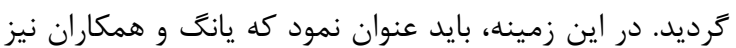

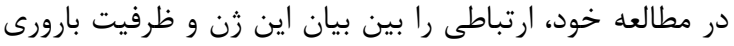
كزارش كرده بودند [ [rاطي

\section{نتيجه تيرى}

درمجموع، با توجه به يافتههاى مطالعه حاضر مىتوان كفت كه زن ADAMTS-1 در روند تكامل و رسيدهشدن تخمك، باضئ

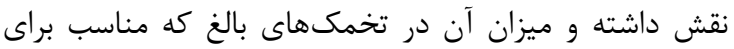

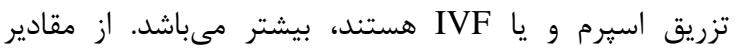

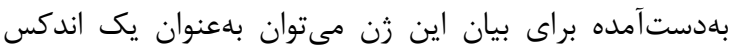

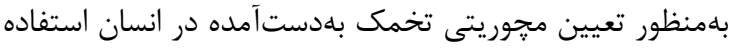


مى كردد كه از تحقيقات كَتردهتر با حجم نمونههاى بيشتر

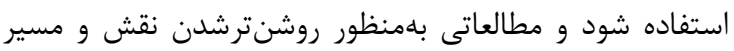
سيخنالينَ اين زن در سلول هاى كومولوس صورت كيرد.

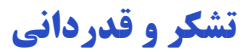

اين مقاله منتج از بايان نامه كارشناسىارشد رشته آناتومى

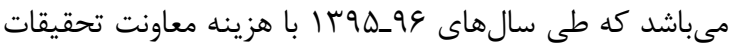

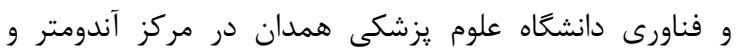

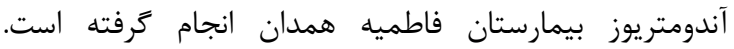
بدينوسيله از زحمات و همكارى اعضا و كارشناس فارسان مركز تحقيقات يادشده و نيز مركز يزشكى مولكولى صميمانه تشكر إنى

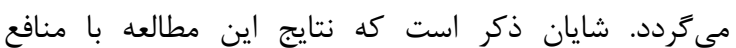

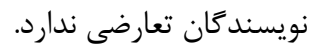

\section{REFERENCES}

1. Dekel N, Beers WH. Development of the rat oocyte in vitro: inhibition and induction of maturation in the presence or absence of the cumulus oophorus. Dev Biol. 1980;75(2):24754. PMID: 6154623

2. Larsen WJ, Wert SE, Brunner GD. A dramatic loss of cumulus cell gap junctions is correlated with germinal vesicle breakdown in rat oocytes. Dev Biol. 1986;113(2):517-21. PMID: 3949077

3. Eppig JJ. A comparison between oocyte growth in coculture with granulosa cells and oocytes with granulosa cell-oocyte junctional contact maintained in vitro. $J$ Exp Zool. 1979;209(2):345-53. PMID: 512597 DOI: 10.1002/jez. $\underline{1402090216}$

4. Gilchrist RB, Ritter LJ, Armstrong DT. Oocyte-somatic cell interactions during follicle development in mammals. Anim
نتايج نشان داد كه ADAMTS-1 در سلولهاى كومولوس زنان با فعاليت طبيعى تخمدان وجود دارد. همجنين، مشاهده

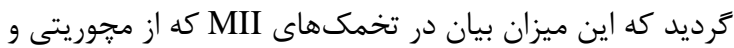
تكامل برخوردار هستند، در مقايسه با تخمكهاى مىباشد.

در مطالعات قبلى عنوان شده است كه ADAMTS-1

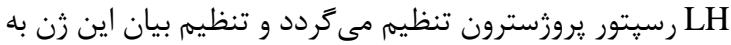
LH/HCG در اين راستا، شوزو و همكاران در بررسى موشها نشا نشان دادند

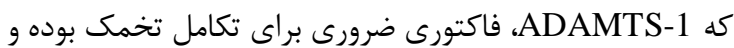

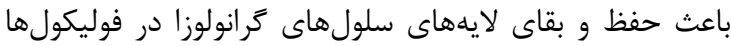

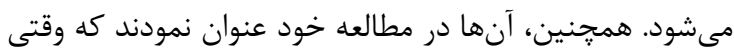

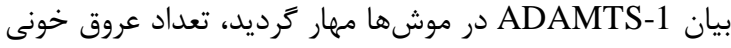
بزر كَ در ناحيه ميانى بهشدت كاهش يافت كه اين امر احتمالاً

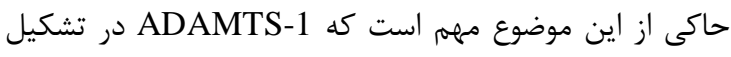

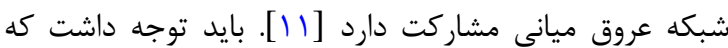
ADAMTS-1

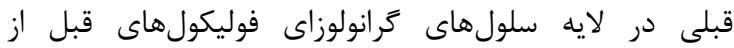

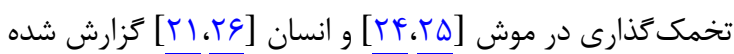



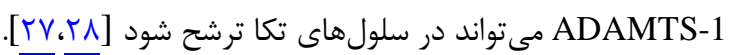

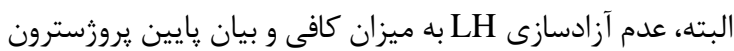

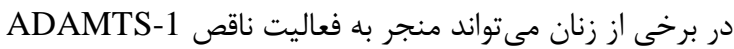

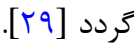
لازم به ذكر است كه ارتباط بين بيان ADAMTS-1

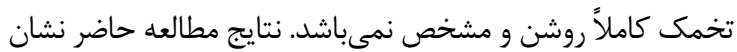
داد كه ميزان بيان ADAMTS-1 در تخمكهاى GV

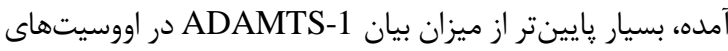
رسيده بوده است.



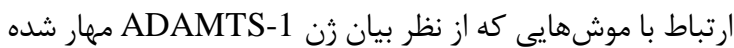

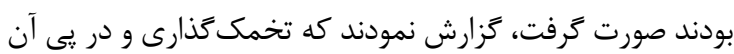

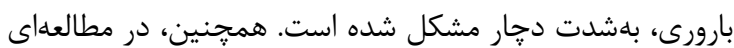
كه بهتازگى در ارتباط با انسان انجام شده است، يانت و همكاران

Reprod Sci. 2004;82-83:431-46. PMID: 15271471 DOI: 10.1016/j.anireprosci.2004.05.017

5. Pangas SA, Matzuk MM. The art and artifact of GDF9 activity: cumulus expansion and the cumulus expansionenabling factor. Biol Reprod. 2005;73(4):582-5. PMID: 15917343 DOI: $10.1095 /$ biolreprod.105.042127

6. Fauser B, Diedrich K, Bouchard P, Dominguez F, Matzuk M, Franks S, et al. Contemporary genetic technologies and female reproduction. Hum Reprod Update. 2011;17(6):82947. PMID: 21896560 DOI: $10.1093 /$ humupd/dmr033

7. Tanghe S, Van Soom A, Nauwynck H, Coryn M, de Kruif A. Minireview: functions of the cumulus oophorus during oocyte maturation, ovulation, and fertilization. Mol Reprod Dev. 2002;61(3):414-24. PMID: 11835587 DOI: 10.1002/ mrd.10102 
8. Yang YJ, Zhang YJ, Li Y. Ultrastructure of human oocytes of different maturity stages and the alteration during in vitro maturation. Fertil Steril. 2009;62(1):396.e1-6. PMID: 19362300 DOI: $10.1016 /$ j.fertnstert.2009.02.010

9. Russell DL, Brown HM, Dunning KR. ADAMTS proteases in fertility. Matrix Biol. 2015;44-46:54-63. PMID: 25818315 DOI: 10.1016/j.matbio.2015.03.007

10. Demircan K, Cömertoğlu İ, Akyol S, Yiğitoğlu BN, Sarıkaya E. A new biological marker candidate in female reproductive system diseases: matrix metalloproteinase with thrombospondin motifs (ADAMTS). J Turk German Gynecol Assoc. 2014;15(4):250-4. PMID: 25584036 DOI: 10.5152/ jtgga.2014.14206

11. Shozu M, Minami N, Yokoyama H, Inoue M, Kurihara H, Matsushima K, et al. ADAMTS-1 is involved in normal follicular development, ovulatory process and organization of the medullary vascular network in the ovary. $J \mathrm{Mol}$ Endocrinol. 2005;35(2):343-55. PMID: 16216914 DOI: 10.1677/jme.1.01735

12. Brown HM, Dunning KR, Robker RL, Pritchard M, Russell DL. Requirement for ADAMTS-1 in extracellular matrix remodeling during ovarian folliculogenesis and lymphangiogenesis. Dev Biol. 2006;300(2):699-709. PMID: 17097630 DOI: $10.1016 /$ j.ydbio.2006.10.012

13. Xiao S, Li Y, Li T, Chen M, Xu Y, Wen Y, et al. Evidence for decreased expression of ADAMTS-1 associated with impaired oocyte quality in PCOS patients. J Clin Endocrinol Metab. 2014;99(6):E1015-21. PMID: 24646063 DOI: 10.1210/jc.2013-4177

14. Anderson RA, Sciorio R, Kinnell H, Bayne RA, Thong KJ, De Sousa PA, et al. Cumulus gene expression as a predictor of human oocyte fertilisation, embryo development and competence to establish a pregnancy. Reproduction. 2009;138(4):629-37. PMID: 19602522 DOI: 10.1530/REP09-0144

15. Adriaenssens T, Wathlet S, Segers I, Verheyen G, De Vos A, Van der Elst J, et al. Cumulus cell gene expression is associated with oocyte developmental quality and influenced by patient and treatment characteristics. Hum Reprod. 2010;25(5):1259-70. PMID: 20228394 DOI: 10.1093/ humrep/deq049

16. European and Middle East Orgalutran Study Group. Comparable clinical outcome using the GnRH antagonist ganirelix or a long protocol of the GnRH agonist triptorelin for the prevention of premature LH surges in women undergoing ovarian stimulation. Hum Reprod. 2001; 16(4):644-51. PMID: 11278211

17. Al-Delemi DH, Al-Gewary AK, Ali Jeddoa ZM. Identification of the expression level to LH-r gene in dominant and cystic ovarian follicles cells of the cows. $J$ Dairy Vet Anim Res. 2014;1(3):17.

18. Shindo T, Kurihara H, Kuno K, Yokoyama H, Wada T, Kurihara Y, et al. ADAMTS-1: a metalloproteinasedisintegrin essential for normal growth, fertility, and organ morphology and function. J Clin Invest. 2000;105(10):134552. PMID: 10811842 DOI: $10.1172 /$ JCI8635

19. Mittaz L, Russell D, Wilson T, Brasted M, Tkalcevic J, Salamonsen L, et al. Adamts-1 is essential for the development and function of the urogenital system. Biol
Reprod. 2004;70(4):1096-105. PMID: 14668204 DOI: 10.1095/biolreprod.103.023911

20. Robker RL, Russell DL, Espey LL, Lydon JP, O'Malley BW, Richards JS. Progesterone-regulated genes in the ovulation process: ADAMTS-1 and cathepsin L proteases. Proc Natl Acad Sci U S A. 2000;97(9):4689-94. PMID: 10781075 DOI: 10.1073/pnas.080073497

21. Yung Y, Maman E, Konopnicki S, Cohen B, Brengauz M, Lojkin I, et al. ADAMTS-1: a new human ovulatory geneandacumulus marker for fertilization capacity. Mol Cell Endocrinol. 2010;328(1-2):104-8. PMID: 20655981 DOI: 10.1016/j.mce.2010.07.019

22. Robker RL, Russell DL, Yoshioka S, Sharma SC, Lydon JP, O'Malley BW, et al. Ovulation: a multi-gene, multi-step process. Steroids. 2000;65(10):559-70. PMID: 11108860

23. Doyle KM, Russell DL, Sriraman V, Richards JS. Coordinate transcription of the ADAMTS-1 gene by luteinizing hormone and progesterone receptor. Mol Endocrinol. 2004; 18(10):2463-78. PMID: 15256533 DOI: $10.1210 /$ me.20030380

24. Russell DL, Doyle KM, Ochsner SA, Sandy JD, Richards JS. Processing and localization of ADAMTS- 1 and proteolytic cleavage of versican during cumulus matrix expansion and ovulation. J Biol Chem. 2003;278(43):42330-9. PMID: 12907688 DOI: $10.1074 / \mathrm{jbc}$ M300519200

25. Espey LL, Yoshioka S, Russell DL, Robker RL, Fujii S, Richards JS. Ovarian expression of a disintegrin and metalloproteinase with thrombospondin motifs during ovulation in the gonadotropin-primed immature rat. Biol Reprod. 2000;62(4):1090-5. PMID: 10727282

26. Freimann S, Ben-Ami I, Dantes A, Armon L, Ya'cov-Klein $\mathrm{AB}$, Ron-El R, et al. Differential expression of genes coding for EGF-like factors and ADAMTS1 following gonadotropin stimulation in normal and transformed human granulosa cells. Biochem Biophys Res Commun. 2005;333(3):935-43. PMID: 15967414 DOI: 10.1016/j.bbrc.2005.04.177

27. Madan P, Bridges PJ, Komar CM, Beristain AG, Rajamahendran R, Fortune JE, et al. Expression of messenger RNA for ADAMTS subtypes changes in the periovulatory follicle after the gonadotropin surge and during luteal development and regression in cattle. Biol Reprod. 2003;69(5):1506-14. PMID: 12855604 DOI: 10.1095/ biolreprod.102.013714

28. Boerboom D, Russell DL, Richards JS, Sirois J. Regulation of transcripts encoding ADAMTS-1 (a disintegrin and metalloproteinase with thrombospondin-like motifs-1) and progesterone receptor by human chorionic gonadotropin in equine preovulatory follicles. $J$ Mol Endocrinol. 2003;31(3):473-85. PMID: 14664708

29. Schuster J, Karlsson T, Karlstrom PO, Poromaa IS, Dahl N. Downregulation of progesterone receptor membrane component 1 (PGRMC1) in peripheral nucleated blood cells associated with premature ovarian failure (POF) and polycystic ovary syndrome (PCOS). Reprod Biol Endocrinol. 2010;8:58. PMID: 20537145 DOI: 10.1186/1477-7827-8-58

30. Wu Y, Wu J, Lee DY, Yee A, Cao L, Zhang Y, et al. Versican protects cells from oxidative stress-induced apoptosis. Matrix Biol. 2005;24(1):3-13. PMID: 15748997 DOI: 10.1016/ j.matbio.2004.11.007 